\title{
Effect of tiotropium bromide on circadian variation in airflow limitation in chronic obstructive pulmonary disease
}

\author{
P M A Calverley, A Lee, L Towse, J van Noord, T J Witek, S Kelsen
}

Thorax 2003:58:855-860

See end of article for authors' affiliations

Correspondence to: Professor P M A Calverley, Pulmonary and Rehabilitation Research Group, Department of Medicine, University Hospital Aintree, Liverpool L9 7AL, UK.

pmaca@@liverpool.ac.uk

Revised version received 1 May 2003

Accepted for publication 27 May 2003
Background: In chronic obstructive pulmonary disease (COPD), the degree of circadian variation in forced expiratory volume in 1 second $\left(\mathrm{FEV}_{1}\right)$ and the influence of anticholinergic blockade is not known. Tiotropium is a long acting inhaled anticholinergic bronchodilator that increases daytime $\mathrm{FEV}_{1}$ in COPD. We hypothesised that tiotropium would modify the overnight change in $\mathrm{FEV}_{1}$, and this would be unaffected by the timing of drug administration.

Methods: A double blind, randomised, placebo controlled trial was conducted with tiotropium $18 \mathrm{mg}$ once daily in the morning (09.00 hours), evening (21.00 hours), or an identical placebo. Patients with stable $\operatorname{COPD}\left(\mathrm{n}=121, \mathrm{FEV}_{1}=41 \%\right.$ predicted) underwent spirometric tests every 3 hours for 24 hours at baseline and after 6 weeks of treatment.

Results: There were no significant differences at baseline between the groups. Tiotropium improved mean (SE) FEV 1 (over 24 hours) in the morning (1.11 (0.03) I) and evening (1.06 (0.03) I) groups compared with placebo $(0.90(0.03) \mathrm{l})$, and nocturnal $\mathrm{FEV}_{1}$ (mean of 03.00 and 06.00 hours) in the morning (1.03 $(0.03) \mathrm{I})$ and evening (1.04 (0.03) I) groups compared with placebo $(0.82(0.03)$ I) at the 6 week visit $(p<0.01)$. FEV 1 before morning or evening dosing was similar, while the peak $\mathrm{FEV}_{1}$ moved later in the day with active treatment. The mean percentage change in $\mathrm{FEV}_{1}$ from 09.00 hours to 03.00 hours (the nocturnal decline in $\mathrm{FEV}_{1}$ ) was $-2.8 \%$ in the morning group, $-1.0 \%$ in the evening group, and $-12.8 \%$ in the placebo group. The magnitude of the peak to trough change in $\mathrm{FEV}_{1}$ was not statistically different. Conclusions: Tiotropium produced sustained bronchodilation throughout the 24 hour day without necessarily abolishing circadian variation in airway calibre.
M any patients with respiratory disease complain of symptoms which are worse during the night or in the early morning. This has been well documented in bronchial asthma ${ }^{12}$ but is also reported by patients with chronic obstructive pulmonary disease (COPD). ${ }^{3-5}$ In patients with asthma the symptoms have usually been ascribed to a substantial increase in the normal circadian variation in airway calibre, ${ }^{6}$ but data in COPD are less convincing and have relied on unsupervised home peak expiratory flow (PEF) recording. Nonetheless, a circadian variation of $16 \mathrm{l} /$ min per day has been reported in COPD and is substantially less than in asthmatic subjects.

There is general agreement that central cholinergic mechanisms are the major determinants of this variation in airway calibre. ${ }^{8}$ However, this has been difficult to test in man as the duration of action of existing anticholinergic drugs does not completely span the overnight period. ${ }^{9}$ Moreover, the side effects of systemically administered anticholinergic drugs preclude the chronic treatment required to assess this response, as does their attendant sleep disruption. Nonetheless, there are data that suggest that inhaled oxitropium bromide can reduce the overnight fall in PEF in nocturnal asthma. ${ }^{10}$

Tiotropium bromide is a new long acting inhaled anticholinergic bronchodilator that improves lung function for 24 hours after once daily dosing. The pharmacological properties of muscarinic receptor kinetic subselectivity ${ }^{11} 12$ and prolonged binding to the $\mathrm{M}_{3}$ receptor have been proposed as explanations for this prolonged duration of action. $^{13}$ An earlier dose ranging study of single dose tiotropium in patients with COPD showed that, despite significant bronchodilation, a nocturnal decline in $\mathrm{FEV}_{1}$ occurred approximately 15-19 hours after morning inhalation of a single dose. ${ }^{14}$ This change was less marked than that with placebo, suggesting that morning administration of tiotropium partially reverses the nocturnal decline in lung function.

Evening administration of tiotropium has not previously been evaluated. The time of administration may influence the pharmacodynamics of some bronchodilators such as theophylline, with evening administration of certain formulations having a more pronounced effect on lung function during the night. ${ }^{15}$ Similar time dependent effects of dosing have been seen with corticosteroids in asthma. ${ }^{16}{ }^{17}$

In this study we examined whether the circadian variation in $\mathrm{FEV}_{1}$ in patients with COPD was greater than that reported in healthy subjects, whether it could be abolished or reduced by sustained anticholinergic blockade in the airways, and whether the timing of the dose of tiotropium influenced its effect on overnight $\mathrm{FEV}_{1}$ compared with placebo treated patients.

\section{METHODS}

\section{Subjects}

All patients recruited were at least 40 years old with a smoking history of at least 10 pack years and a clinical diagnosis and spirometric parameters compatible with COPD as defined by the American Thoracic Society (ATS). ${ }^{18}$ Their $\mathrm{FEV}_{1} / \mathrm{FVC}$ ratio was less than $70 \%$ and their absolute $\mathrm{FEV}_{1}$ was 25-65\% predicted using the European Community for Coal and Steel (ECCS) reference values. ${ }^{19}$ Patients with a history of asthma, allergic rhinitis, or atopy, or a total eosinophil count $\geqslant 600 / \mathrm{mm}^{3}$ were excluded, as were those with significant diseases other than COPD. No patient had experienced an exacerbation of COPD within the preceding 4 weeks. Medications not permitted after the run in phase were short acting inhaled anticholinergic drugs, long acting inhaled $\beta$ agonists, oral $\beta$ agonists, and theophylline. Use of 
other concurrent medication was required to be stable during the study period. The protocol was approved by local institution review boards and informed consent was obtained from all patients.

\section{Study design}

A 6 week, multicentre, randomised, double blind, double dummy, parallel group design was used. Three treatment arms were compared: tiotropium $18 \mu \mathrm{g}$ daily administered at 09.00 hours (Tio-AM), tiotropium $18 \mu \mathrm{g}$ daily administered at 21.00 hours (Tio-PM), and placebo. All patients inhaled the contents of one capsule twice daily (either placebo or tiotropium, depending on the group). The times of study administration selected were based on the anticipated average time that a person might take morning or evening medication, considering the study design needed to separate the dose-time interval by 12 hours. Study medication was administered by a dry powder device (HandiHaler).

After initial screening, patients entered a 7 day baseline period to ensure clinical stability (no exacerbations). They attended the clinic where spirometric tests were performed 3 hourly over a 24 hour period, at the end of which they received their first morning dose of study medication. They were instructed to take the study medication in the morning (09.00 hours) and evening (21.00 hours) and to record their morning and evening PEF throughout the study in a diary card immediately before administering study medication.

After 6 weeks the patients attended for their second clinic visit. Spirometric assessment began before the administration of the evening dose of medication. Patients remained in the clinic overnight and spirometric tests were again repeated 3 hourly throughout the following day (including overnight measurements and immediately before the morning dose of study medication). Patients were awakened for spirometric testing if necessary.

A continuous 24 ECG (Holter monitor) was recorded during the patients' stay in the clinic at baseline and at 6 weeks. Analysis of the Holter ECG tapes was performed by Hertford Medical BV, Maasdam, The Netherlands by investigators blinded to the purpose of the study. Adverse events were monitored throughout the baseline and 6 week treatment periods.

\section{Study procedures}

Baseline spirometric tests were conducted between 08.00 and 12.00 hours. They were conducted in triplicate and met ATS standards of reproducibility. ${ }^{20}$ The highest values of $\mathrm{FEV}_{1}$ and FVC from three reproducible tracings were recorded. Identical portable electronic spirometers (Microlab 3300 Spirometer; Micromedical, Kent, UK) were used for all measurements at all centres. Home PEF recordings were made using a Personal Best Peak Flow Meter (Health Scan Products Inc, Cedar Grove, NJ, USA) and were recorded as the best of three efforts in the morning and the evening.

\section{Data analysis}

The primary end point was the mean change from baseline in $\mathrm{FEV}_{1}$ recorded at 03.00 and 06.00 hours on the morning following the last dose of study medication on visit 4 (after 42 (3) days of treatment). Baseline $\mathrm{FEV}_{1}$ was derived from the measurements recorded at 03.00 and 06.00 hours before the administration of the study drug on visit 2 (day 1). The overall steady state bronchodilator efficacy of tiotropium was determined by the mean $\mathrm{FEV}_{1}$ response measured over a 24 hour time interval on visit 4 . The mean $\mathrm{FEV}_{1}$ at baseline was calculated as the mean of the 3 hourly readings measured over 24 hours from 09.00 to 09.00 at visit 2 . The mean response was defined as the difference between the mean $\mathrm{FEV}_{1}$ at baseline (visit 2) and the mean $\mathrm{FEV}_{1}$ at the end of treatment (visit 4).

The sample size calculation was based on data from previous studies of the effect of tiotropium on $\mathrm{FEV}_{1}$ in COPD.${ }^{14}$ Assuming a standard deviation of $0.17 \mathrm{l}$ for $\mathrm{FEV}_{1},{ }^{21} \mathrm{a}$ sample size of 30 patients per treatment group would be sufficient to detect a difference of $0.15 \mathrm{l}$ in $\mathrm{FEV}_{\mathrm{l}}$ between treatment groups at a $5 \%$ level of significance and $90 \%$ power using a two tailed $t$ test.

Data are presented as mean (SD) for the population and SE for between-group comparisons. Analysis of covariance with terms for treatment and centre and baseline as a covariate was used as the statistical model for all efficacy analyses. The baseline value was included in the analysis of covariance model as a covariate to adjust for any baseline differences between treatment groups. Patients were excluded from individual analysis if adequate data were not available (for example, missing baseline data). Differences were accepted as being statistically significant at $\mathrm{p}<0.05$. Circadian variation in peak flow and $\mathrm{FEV}_{1}$ was calculated as the difference between the highest and lowest values divided by the mean of the values available for that period-that is, all $\mathrm{FEV}_{1}$ measurements during the 24 hour period and all PEF measurements during the week of study. However, the study was not originally powered to examine circadian variation and the analyses performed for this evaluation were conducted post hoc.

\section{RESULTS}

\section{Demographic data}

Patient baseline features for the three treatment groups are presented in table 1 . The mean age for the groups combined was 65.8 years, $62 \%$ were men, and the group mean $\mathrm{FEV}_{1}$ was $1.08 \mathrm{l}$ ( $40.8 \%$ predicted). The mean smoking history was 44 pack years, with $62 \%$ of the total population being exsmokers. The groups did not differ in their pulmonary function or in their usual pulmonary medication before randomisation (table 1).

\section{Spirometric parameters}

Forced expiratory volume in 1 second $\left(F E V_{1}\right)$

The mean (SE) nocturnal $\mathrm{FEV}_{1}$ (mean $\mathrm{FEV}_{1}$ at 03.00 and 06.00 hours) for the Tio-AM, Tio-PM, and placebo groups and the corresponding overall steady state $\mathrm{FEV}_{1}$ (mean over 24 hours) values are presented in table 2 . The differences from placebo in both the morning and evening dosing groups as well as the nocturnal $\mathrm{FEV}_{1}$ were statistically significant $(p<0.05)$ at all time points on day 42 . The baseline 24 hour spirometric recordings showed significant circadian variation in $\mathrm{FEV}_{1}$ in all three patient groups with the highest values recorded at 09.00 hours on the study day and the lowest values occurring at either 03.00 or 06.00 hours on the following morning (fig $1 \mathrm{~A})$. The group mean change in $\mathrm{FEV}_{1}$ between 09.00 and 03.00 hours at baseline was: $-180 \mathrm{ml}$ in Tio-AM, $-200 \mathrm{ml}$ in Tio-PM, and $-120 \mathrm{ml}$ in the placebo group, corresponding to 03.00 hour absolute values of $\mathrm{FEV}_{1}$ of $0.88,0.84$, and $0.90 \mathrm{l}$, respectively. The mean $\mathrm{FEV}_{1}$ over the 24 hour day was $0.96,0.95$ and $0.96 \mathrm{l}$ for the Tio-AM, Tio-PM, and placebo groups, respectively. The mean circadian variation for each group was 33.3\%, 35.6\% and $25.9 \%$, respectively. There was considerable intersubject variability and these values did not differ statistically between the groups (ANOVA), but in the pairwise comparisons the variation in the Tio-PM group was higher than in the placebo group $(p=0.03)$. However, the baseline variability before treatment was lower in the placebo group and this might influence the results.

When the $\mathrm{FEV}_{1}$ profile was repeated after treatment, patients receiving placebo had a lower 24 hour mean $\mathrm{FEV}_{1}$ 
Table 1 Demographic characteristics of patients at screening $(n=121)$

\begin{tabular}{|c|c|c|c|c|}
\hline & $\begin{array}{l}\text { Tiotropium (pm) } \\
(\mathrm{n}=43)\end{array}$ & $\begin{array}{l}\text { Tiotropium (am) } \\
(\mathrm{n}=38)\end{array}$ & Placebo $(n=40)$ & Total $(n=121)$ \\
\hline Men (n) & 28 & 21 & 26 & 75 \\
\hline Age (years)* & $66.1(6.6)$ & $64.9(7.7)$ & $66.5(9.4)$ & $65.8(7.9)$ \\
\hline Duration of COPD (years) ${ }^{*}$ & $10.0(8.5)$ & $12.3(12.3)$ & $9.9(7.9)$ & $10.7(9.7)$ \\
\hline $\begin{array}{l}\text { Baseline spirometry:* } \\
\text { FEV }\end{array}$ & & & & \\
\hline $\mathrm{FEV}_{1}$ (I) & $1.09(0.38)$ & $1.12(0.45)$ & $1.04(0.33)$ & $1.08(0.39)$ \\
\hline $\mathrm{FEV}_{1}(\%$ predicted $)$ & $41.8(14.0)$ & $41.9(13.5)$ & $38.6(9.6)$ & $40.8(12.5)$ \\
\hline FVC (I) & $2.14(0.67)$ & $2.19(0.68)$ & $2.15(0.71)$ & $2.16(0.68)$ \\
\hline $\mathrm{FEV}_{1} / \mathrm{FVC}(\%)$ & $51.8(11.0)$ & $50.9(11.0)$ & $49.6(9.3)$ & 50.8 (10.4) \\
\hline $\begin{array}{l}\text { Total taking pulmonary } \\
\text { medication during the } \\
\text { baseline period }\end{array}$ & 41 (95.3\%) & $36(94.7 \%)$ & $37(92.5 \%)$ & 114 \\
\hline Anticholinergic drugs & 15 (34.9\%) & $14(36.8 \%)$ & $18(45.0 \%)$ & 47 \\
\hline Beta adrenergics (inhaled) & ) 34 (79.1\%) & $34(89.5 \%)$ & $35(87.5 \%)$ & 103 \\
\hline Beta adrenergics (oral) & $3(7.0 \%)$ & $4(10.5 \%)$ & $4(10.0 \%)$ & 11 \\
\hline Mucolytic agents & $1(2.3 \%)$ & $3(7.9 \%)$ & $3(7.5 \%)$ & 7 \\
\hline Steroid (inhaled) & $31(72.1 \%)$ & $27(71.1 \%)$ & $27(67.5 \%)$ & 85 \\
\hline Steroid (oral) & $0(0 \%)$ & $0(0 \%)$ & $2(5.0 \%)$ & 2 \\
\hline Theophylline & $2(4.7 \%)$ & $1(2.6 \%)$ & $2(5.0 \%)$ & 5 \\
\hline
\end{tabular}

(0.91 (0.02) l) which was statistically lower than at the baseline visit $(0.96(0.02)$ l). On this occasion, the peak value occurred at 12.00 hours with the minimum $\mathrm{FEV}_{1}$ again being recorded between 03.00 and 06.00 hours on the following day, corresponding to an absolute $\mathrm{FEV}_{1}$ of $0.82 \mathrm{l}$ (fig 1B).

In both tiotropium groups the $\mathrm{FEV}_{1}$ increased significantly at all time points during the 24 hour observation period compared with placebo (fig $1 \mathrm{~B}$ ). In patients treated with tiotropium the highest $\mathrm{FEV}_{1}$ now occurred at 12.00 hours, but the nadir remained between 03.00 and 06.00 hours. There was a non-significant trend towards a reduction in the magnitude of overnight decline in $\mathrm{FEV}_{1}$ compared with placebo when this was expressed as a percentage change from the mean at 09.00 hours (fig 2), but not as an absolute change from the mean daily $\mathrm{FEV}_{1}$ value (Tio-AM $=60 \mathrm{ml}$, Tio-PM $=48 \mathrm{ml}$, placebo $=56 \mathrm{ml}$ ).

Individual maximum variation was calculated as the difference between maximum and minimum $\mathrm{FEV}_{1}$ expressed as a proportional change from the minimum $(100 \times$ (maximum - minimum)/minimum). At baseline the mean maximum variation was $41.6 \%, 46.5 \%$, and $30.2 \%$ for TioAM, Tio-PM, and placebo, respectively. After treatment the mean maximum variation declined in the Tio-AM (34.5\%) and the Tio-PM (37.2\%) groups but was similar to baseline in the placebo group $(32.7 \%)$.

\section{Forced vital capacity}

The pattern of nocturnal FVC (mean FVC at 03.00 and 06.00 hours) and overall steady state FVC (mean over 24 hours) was similar to the $\mathrm{FEV}_{1}$ responses, and both tiotropium groups were statistically better than placebo $(\mathrm{p}=0.0001)$. The mean (SE) nocturnal FVC for the Tio-AM, Tio-PM, and placebo groups and the corresponding overall steady state FVC values are presented in table 3. No statistically significant differences were seen between the two tiotropium dosing groups with respect to the nocturnal FVC $(p=0.61)$ and overall steady state FVC $(p=0.35)$. As with $\mathrm{FEV}_{1}$, the FVC profile after 6 weeks of treatment showed that both tiotropium groups were consistently better than the placebo group throughout the 24 hour observation period.

\section{Peak expiratory flow}

The mean morning and evening PEF during the baseline period were comparable across the three treatment groups (table 4). The weekly mean morning and evening PEF for both tiotropium groups was statistically better than for placebo ( $\mathrm{p}<0.02$, fig 3 ). For both tiotropium groups the mean weekly morning and evening PEF increased after l week on treatment, and remained consistently better than placebo throughout the 6 weeks of treatment.

\section{Adverse events}

COPD exacerbations and upper respiratory tract infection were more common with placebo than with Tio-AM and TioPM, although the differences were not statistically significant. Exacerbations of COPD and upper respiratory tract infections were diagnosed by the physician and reported as adverse events. Eight patients $(20.0 \%)$ in the placebo group had a COPD exacerbation compared with four patients

Table 2 Mean* (SE) nocturnal forced expiratory volume in 1 second $\left(\mathrm{FEV}_{1}\right)$ and overall steady state $F E V_{1}$ differences between treatment groups after 6 weeks of study drug

\begin{tabular}{llllll}
\hline Treatment & Mean (SE) & Comparison & Difference (SE) & p value & $95 \% \mathrm{Cl}$ \\
\hline $\begin{array}{l}\text { Nocturnal } \\
\text { FEV }\end{array}$ & & & & & \\
AM & $1.03(0.03)$ & AM - Placebo & $0.21(0.04)$ & 0.0001 & $(0.13$ to 0.29$)$ \\
PM & $1.04(0.03)$ & PM - Placebo & $0.21(0.04)$ & 0.0001 & $(0.13$ to 0.29$)$ \\
Placebo & $0.82(0.03)$ & AM - PM & $-0.01(0.04)$ & 0.8529 & $(-0.09$ to 0.07$)$ \\
Steady state & & & & & \\
FEV & & & & \\
AM & $1.11(0.03)$ & AM - Placebo & $0.21(0.04)$ & 0.0001 & $(0.13$ to 0.29$)$ \\
PM & $1.06(0.03)$ & PM - Placebo & $0.16(0.04)$ & 0.0001 & $(0.09$ to 0.24$)$ \\
Placebo & $0.90(0.03)$ & AM - PM & $0.05(0.04)$ & 0.2127 & $(-0.03$ to 0.12$)$ \\
\hline
\end{tabular}

${ }^{*}$ Means are adjusted for centre and baseline. 

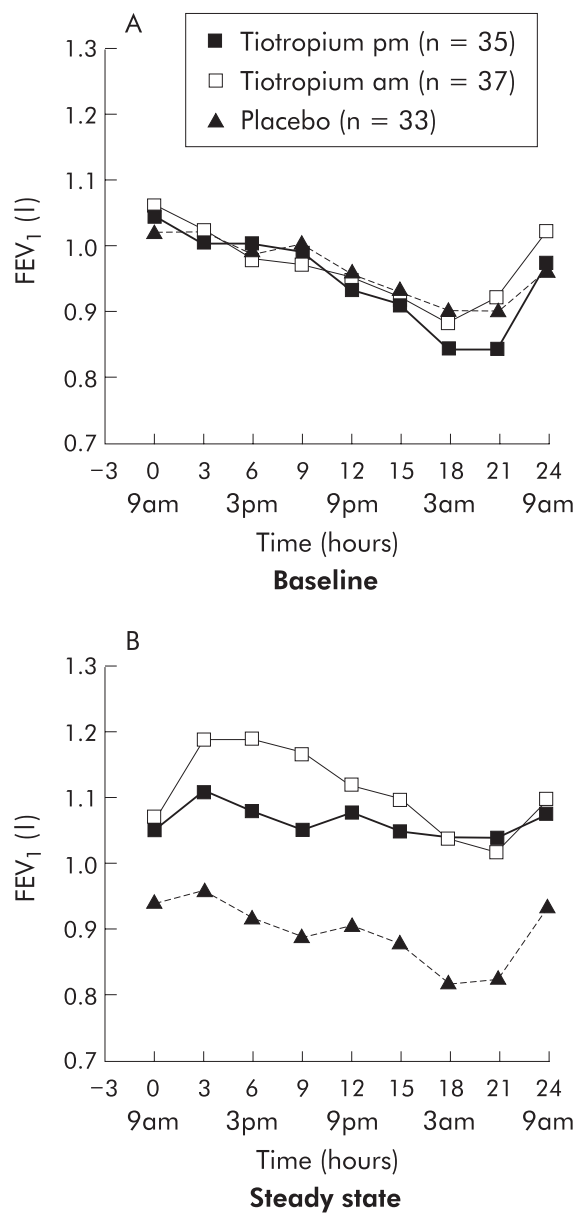

Figure 1 Mean forced expiratory volume in 1 second $\left(\mathrm{FEV}_{1}\right)$ in litres over 24 hours (A) at baseline and (B) after 6 weeks (steady state) of tiotropium in the evening (pm), tiotropium in the morning (am), or placebo.

(9.3\%) in the Tio-PM group and one $(2.6 \%)$ in the Tio-AM group. Six patients $(15.0 \%)$ in the placebo group experienced upper respiratory tract infection compared with three $(7.0 \%)$ in the Tio-PM group and one $(2.6 \%)$ in the Tio-AM group. There were no differences in other adverse events in the tiotropium groups compared with the placebo group. Treatment with tiotropium was not associated with cardiac rhythm or heart rate abnormalities as assessed by 24 hour Holter monitoring.

\section{DISCUSSION}

Like many other biological variables, airway calibre exhibits a circadian variation during the 24 hour day with maximum values occurring around noon and the minimum values in the early morning. ${ }^{22}$ This variability is characteristic of bronchial asthma and is associated with increased levels of inflammatory mediators in the airways during sleep. ${ }^{16}$ The practice of defining variability by changes in morning and evening PEF has been transferred to patients with COPD where, contrary to the current definition of "relatively little variation in airflow calibre", ${ }^{23}$ several studies have shown evidence of circadian variation. ${ }^{4}{ }^{24-27}$ Using the PEF in COPD is potentially misleading as the measurement is effort dependent and underestimates the impairment of $\mathrm{FEV}_{1}$ in COPD. ${ }^{19}$ Previous reports have significant limitations. They included only small numbers of patients and did not obtain measurements during the night. ${ }^{7426}$ Some failed to include a control limb when studying bronchodilator effects ${ }^{24}$ or

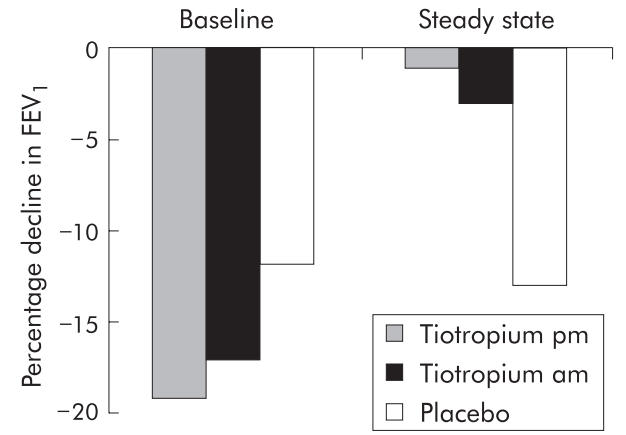

Figure 2 Proportional nocturnal decline in forced expiratory volume in 1 second $\left(\mathrm{FEV}_{1}\right)$ at baseline and after 6 weeks of study drug (steady state). Percentage decline in $\mathrm{FEV}_{1}=\left(\mathrm{FEV}_{1} 9 \mathrm{am}-\mathrm{FEV}_{1} 3 \mathrm{am}\right) / \mathrm{FEV}_{1} 9$ am $\times 100$.

included patients with substantial degrees of bronchodilator responsiveness. ${ }^{4}$ This is the first study to document circadian variation in $\mathrm{FEV}_{1}$ in patients with stable COPD before and after a long acting inhaled bronchodilator and to include measurements during the early morning hours when $\mathrm{FEV}_{1}$ is lowest. Our findings have implications both for the mechanisms underlying this process and the interpretation of the results of treatment trials.

Studies of spirometric tests in normal subjects report a mean maximum change across the day of $200 \mathrm{ml}$ in $\mathrm{FEV}_{1} \cdot{ }^{28}$ Observations in a large population of healthy individuals whose $\mathrm{FEV}_{1}$ was measured on different occasions between 09.00 and 21.00 hours confirm that the peak values occurred around midday. ${ }^{29}$ They suggested that those who are older, smoke cigarettes, or have some respiratory symptoms show a more marked fall in $\mathrm{FEV}_{1}$ in the later evening. At baseline in our patients with COPD there was a mean (SE) daily $F_{1}$ change of 286 (17) $\mathrm{ml}$ for the whole group with the maximum value in the late morning and the minimum in the early hours of the morning. This overall pattern was reproducible over the 6 weeks in the placebo group although the 09.00 value tended to be lower, possibly reflecting differences in the duration of effect of other permitted medications. The FVC data parallel those for $\mathrm{FEV}_{1}$ with no meaningful difference in the $\mathrm{FEV}_{1} / \mathrm{FVC}$ ratio throughout the 24 hour day, an observation supportive of consistent effort in performing the measurements throughout the day. The mean PEF was lower in the morning than in the evening throughout the 6 weeks in the placebo treated patients, varying by $13-17 \mathrm{l} / \mathrm{min}$. These values are similar to those in the only other study to report patients of similar severity. ${ }^{7}$ These mean data mask significant between-week and between-individual variations and highlight the limitation of using measurements of circadian variation where the precise time of measurement is not known.

Lower respiratory system resistance in COPD rises significantly throughout sleep, independent of sleep stage ${ }^{30}$ and, although polysomnographic data were not included in the present study, our data are compatible with this. Increased cholinergic tone in the airway smooth muscle is believed to be a major contributor to this process, but data from the COPD patients treated with tiotropium indicate that this may not be the only factor involved. Tiotropium is an effective inhaled anticholinergic drug which can block methacholine challenge in patients with asthma for long periods. ${ }^{31}$ The mean $\mathrm{FEV}_{1}$ value over the 24 hour day increased after tiotropium and the absolute $\mathrm{FEV}_{1}$ was always higher at any time point after the active drug than the pretreatment baseline and placebo values. The timing of $\mathrm{FEV}_{1}$ variation also changed, with the highest $\mathrm{FEV}_{1}$ occurring between 12.00 
Table 3 Mean* (SE) nocturnal forced vital capacity (FVC) and overall steady state FVC differences between treatment groups after 6 weeks of study drug

\begin{tabular}{|c|c|c|c|c|c|}
\hline Treatment & Mean (SE) & Comparison & Difference (SE) & $p$ value & $95 \% \mathrm{Cl}$ \\
\hline \multicolumn{6}{|c|}{ Nocturnal FVC } \\
\hline AM & $1.99(0.05)$ & AM - Placebo & $0.31(0.07)$ & 0.0001 & $(0.18$ to 0.45$)$ \\
\hline PM & $2.02(0.05)$ & PM - Placebo & 0.35 (0.07) & 0.0001 & (0.22 to 0.48 ) \\
\hline Placebo & $1.68(0.05)$ & $\mathrm{AM}-\mathrm{PM}$ & $-0.03(0.07)$ & 0.6051 & $(-0.16$ to 0.10$)$ \\
\hline \multirow{2}{*}{\multicolumn{6}{|c|}{$\begin{array}{l}\text { Steady state } \\
\text { FVC }\end{array}$}} \\
\hline & & & & & \\
\hline AM & $2.12(0.04)$ & AM - Placebo & $0.32(0.06)$ & 0.0001 & (0.21 to 0.44$)$ \\
\hline PM & $2.07(0.04)$ & PM - Placebo & $0.27(0.06)$ & 0.0001 & $(0.16$ to 0.39$)$ \\
\hline Placebo & $1.79(0.04)$ & $A M-P M$ & $0.05(0.06)$ & 0.3526 & $(-0.06$ to 0.16$)$ \\
\hline
\end{tabular}

and 18.00 hours, a pattern closer to that described in healthy individuals. ${ }^{32}$ Despite this improvement in absolute $\mathrm{FEV}_{1}$, the difference between the highest and lowest values during the day was similar after the active drug whenever given and resembled that reported in normal subjects. ${ }^{22}$ Whether this is due to changes in airway calibre in areas not reached by the inhaler, to different factors modulating airway smooth muscle activation, or simply differences in the control of lung volume or secretion clearance as proposed elsewhere ${ }^{33}$ cannot be resolved by our study.

The data illustrate some of the problems in interpreting bronchial reactivity indices in patients with a low baseline $\mathrm{FEV}_{1}$. If we relate the change in $\mathrm{FEV}_{1}$ after tiotropium administered at 09.00 hours to a specific time point as in fig 2 , reactivity appears to decline even though the absolute change from maximum to minimum is unaffected. Similar problems arise when other indices recommended in population studies are calculated..$^{34}$ This emphasises the need to relate such variables to baseline lung function and helps explain the poor concordance between PEF changes and other measures of bronchial reactivity in patients with COPD. ${ }^{35}$

Although the timing of the dose of some drugs, such as corticosteroids in asthma, ${ }^{16}{ }^{17}$ may influence the subsequent $\mathrm{FEV}_{1}$, this was not seen in these studies with tiotropium in COPD. The absolute change in $\mathrm{FEV}_{1}$ compared with baseline appeared smaller than that reported in some larger trials, ${ }^{36}$ but the changes relative to placebo were similar in magnitude. Nevertheless, the timing of the measurements can influence the end points selected. The 03.00 hours value had a mean difference of $220 \mathrm{ml}$ in the Tio-AM and Tio-PM groups compared with placebo, while the 09.00 hours value had a mean difference of 130 and $110 \mathrm{ml}$, respectively. This dependence on timing may help explain why patients with COPD vary in response to the same drug in different studies.

In summary, we have found that circadian variations in $\mathrm{FEV}_{1}$ are present in patients with COPD. This is likely to contribute to the disturbed sleep seen in such patients and reflected in their daytime symptoms. Although the absolute change in $\mathrm{FEV}_{1}$ over 24 hours is close to normal, it comprises a proportionately greater amount of the waking value and this can complicate the interpretation of the usual measures of bronchial responsiveness. Our findings show that tiotro-

Table 4 Mean (SE) baseline weekly means for morning (PEF am) and evening (PEF pm) peak expiratory flow rates (l/min)

\begin{tabular}{llll}
\hline & $\begin{array}{l}\text { Tiotropium } \\
\mathbf{p m}(\mathbf{n}=40)\end{array}$ & $\begin{array}{l}\text { Tiotropium } \\
\mathbf{a m}(\mathbf{n}=\mathbf{3 7})\end{array}$ & $\begin{array}{l}\text { Placebo } \\
(\mathbf{n}=\mathbf{3 4})\end{array}$ \\
\hline PEF am & $209(13)$ & $195(11)$ & $217(15)$ \\
PEF pm & $225(12)$ & $205(11)$ & $223(15)$ \\
\hline
\end{tabular}

pium once daily, whether administered in the morning or evening, results in sustained improvements in spirometric indices throughout the 24 hours, including improvement in the early morning nadir in spirometric values, without necessarily affecting circadian variability.

\section{ACKNOWLEDGEMENTS}

The authors acknowledge the contributions of the following investigators who participated in the study: Dr N M Foley, Royal United Hospital, Bath, UK; Dr N K Harrison, Morriston Hospital, Swansea, UK; Dr S J Langley, Wythenshawe Hospital, Manchester, UK; Dr B R O'Driscoll, Hope Hospital, Salford, UK; Dr J A van Noord, De Wever Hospital, Heerlen, The Netherlands; Dr R J White, Frenchay NHS Trust, Bristol, UK; Dr A J Winning, West Middlesex University Hospital, Isleworth, UK.
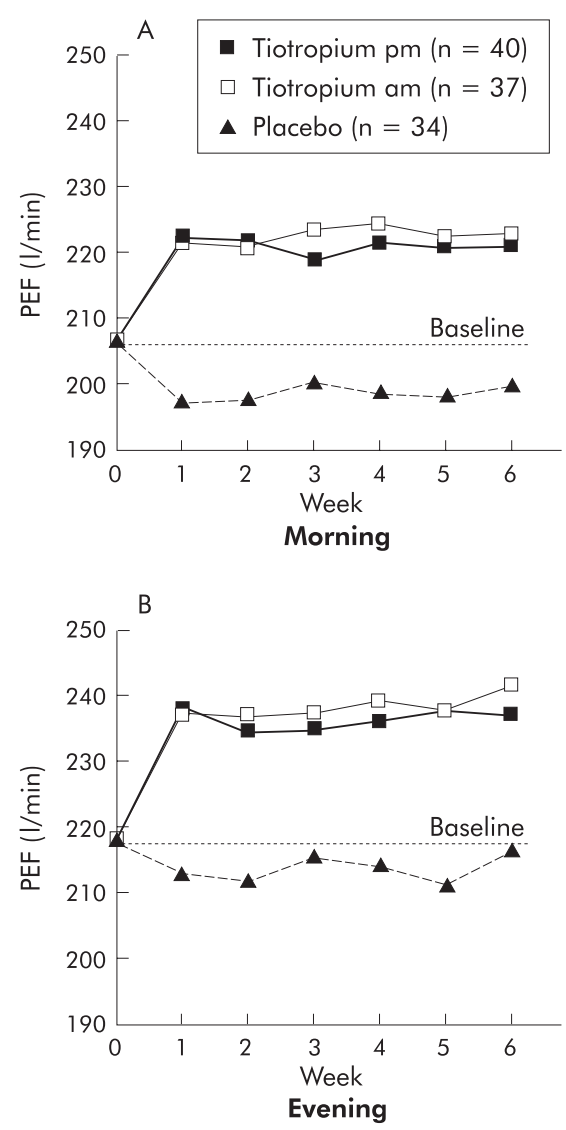

Figure 3 The mean of the weekly means for $(A)$ morning and $(B)$ evening PEF (I/min) over 6 weeks of treatment with either tiotropium in the evening $(\mathrm{pm})$, tiotropium in the morning (am), or placebo. 


\section{Authors' affiliations}

P M A Calverley, Department of Medicine, University of Livepool, Liverpool, UK

J van Noord, Atrium Medisch Centrum, Heerlen, The Netherlands A Lee, L Towse, Boehringer Ingelheim Ltd, Bracknell, Berkshire, UK S Kesten, T J Witek, Boehringer Ingelheim Pharmaceuticals, Ridgefield, Connecticut, USA

PMAC contributed patients to the study, helped develop the data analysis plan and wrote the manuscript together with SK. JVN contributed patients, LT organised the study implementation and AL undertook the statistical analysis. All authors contributed to development of the study protocol, data interpretation, and to the final manuscript.

The study was supported by Boehringer Ingelheim Pharmaceuticals Inc.

\section{REFERENCES}

1 Di Stefano A, Lusuardi M, Braghiroli A, et al. Nocturnal asthma mechanisms and therapy. Lung 1997;175:53-61.

2 Turner-Warwick M. Nocturnal asthma: a study in general practice. J R Coll Gen Pract 1989:39:239-43.

3 Nisar M, Walshaw M, Earis JE, et al. Assessment of reversibility of airway obstruction in patients with chronic obstructive airways disease. Thorax 1990;45: 190-4.

4 Postma DS, Koeter GH, van der Mark TW, et al. The effects of oral slowrelease terbutaline on the circadian variation in spirometry and arterial blood gas levels in patients with chronic airflow obstruction. Chest 1985;87:653-7.

5 Casale R, Pasqualetti P. Cosinor analysis of circadian peak expiratory flow variability in normal subjects, passive smokers, heavy smokers, patients with chronic obstructive pulmonary disease and patients with interstitial lung disease. Respiration 1997;64:251-6.

6 Martin RJ, Banks-Schlegel S. Chronobiology of asthma. Am J Respir Crit Care Med 1998;158:1002-7.

7 Dawkins KD, Muers MF. Diurnal variation in airflow obstruction in chronic bronchitis. Thorax 1981;36:618-21.

8 Postma DS, Keyzer JJ, Koeter GH, et al. Influence of the parasympathetic and sympathetic nervous system on nocturnal bronchial obstruction. Clin Sci 1985;69:251-8.

9 Tashkin DP, Ashutosh K, Bleecker ER, et al. Comparison of the anticholinergic bronchodilator ipratropium bromide with metaproterenol in chronic obstructive pulmonary disease. A 90-day multi-center study. Am J Med 1986;81:81-90.

10 Coe Cl, Barnes PJ. Reduction of nocturnal asthma by an inhaled anticholinergic drug. Chest 1986:90:485-8.

11 Barnes PJ, Belvisi MG, Mak JC, et al. Tiotropium bromide ( $\mathrm{Ba} 679 \mathrm{Br}$ ), a novel long-acting muscarinic antagonist for the treatment of obstructive airways disease. Life Sci 1995;56:853-9

12 Disse BG, Speck A, Rominger KL, et al. Tiotropium (Spiriva): mechanistical considerations and clinical profile in obstructive lung disease. Life $\mathrm{Sci}$ 1999;64:457-64.

13 Disse B. Antimuscarinic treatment for lung diseases from research to clinical practice. Life Sci 2001;68:2557-64.

14 Maesen FP, Smeets JJ, Sledsens TJ, et al. Tiotropium bromide, a new longacting antimuscarinic bronchodilator: a pharmacodynamic study in patients with chronic obstructive pulmonary disease (COPD). Eur Respir J 1995;8:1506-13

15 Smolensky MH, McGovern JP, Scott PH, et al. Chronobiology and asthma. II.Body-time-dependent differences in the kinetics and effects of bronchodilator medications. J Asthma 1987;24:91-134.
16 Beam WR, Weiner DE, Martin RJ. Timing of prednisone and alterations in airways inflammation in nocturnal asthma. Am Rev Respir Dis 1992; 146:1524-30.

17 Pincus DJ, Szefler SJ, Ackerson LM, et al. Chronotherapy of asthma with inhaled steroids: the effect of dosage timing on drug efficacy. J Allergy Clin Immunol 1995;95:1172-8.

18 American Thoracic Society. Standards for the diagnosis and care of patients with chronic obstructive pulmonary disease. Am J Respir Crit Care Med 1995; 152:S77-121.

19 Quanjer PH, Tammeling GJ, Cotes JE, et al. Lung volumes and forced ventilatory flows. Report Working Party Standardization of Lung Function Tests, European Community for Steel and Coal.Official Statement of the European Respiratory Society. Eur Respir J 1993; 16(Suppl):5-40.

20 American Thoracic Society. Standardization of spirometry: 1994 update Am J Respir Crit Care Med 1994;152:1 107-36

21 Tweeddale PM, Alexander F, McHardy GJ. Short term variability in FEV and bronchodilator responsiveness in patients with obstructive ventilatory defects. Thorax 1987;42:487-90.

22 Guberan E, Williams MK, Walford J, et al. Circadian variation of $\mathrm{FEV}_{1}$ in shift workers. Br J Ind Med 1969;26:121-5.

23 COPD Guidelines Group of the Standards of Care Committee of the British Thoracic Society. Guidelines for the management of chronic obstructive pulmonary disease. Thorax 1997;52(Suppl 5):S1-28.

24 Man GC, Chapman KR, Ali SH, et al. Sleep quality and nocturnal respiratory function with once-daily theophylline (Uniphyl) and inhaled salbutamol in patients with COPD. Chest 1996;1 10:648-53

25 Rivington RN, Calcutt L, Hodder RV, et al. Safety and efficacy of once-daily Uniphyl tablets compared with twice-daily Theo-dur tablets in elderly patients with chronic airflow obstruction. Am J Med 1988;85:48-53.

26 Martin RJ, Pak J. Overnight theophylline concentrations and effects on sleep and lung function in chronic obstructive pulmonary disease. Am Rev Respir Dis 1992:145:540-4.

27 van Noord J A, de Munck DR, Bantje TA, et al. Long-term treatment of chronic obstructive pulmonary disease with salmeterol and the additive effect of ipratropium. Eur Respir J 2000;15:878-85.

28 Cochrane GM, Clark JH. A survey of asthma mortality in patients between ages 35 and 64 in the Greater London hospitals in 1971. Thorax 1975;30:300-5.

29 Becker HF, Piper AJ, Flynn WE, et al. Breathing during sleep in patients with nocturnal desaturation. Am J Respir Crit Care Med 1999;159:112-8.

30 Ballard RD, Clover CW, Suh BY. Influence of sleep on respiratory function in emphysema. Am J Respir Crit Care Med 1995;151:945-51.

31 O'Connor BJ, Towse $\sqcup$, Barnes PJ. Prolonged effect of tiotropium bromide on methacholine-induced bronchoconstriction in asthma. Am J Respir Crit Care Med 1996; 154:876-80.

32 Borsboom GJ, van Pelt W, van Houwelingen HC, et al. Diurnal variation in lung function in subgroups from two Dutch populations: consequences for longitudinal analysis. Am J Respir Crit Care Med 1999;159:1163-71.

33 Hetzel MR. The pulmonary clock. Thorax 1981;36:481-6.

34 Higgins BG, Britton JR, Chinn S, et al. Comparison of bronchial reactivity and peak expiratory flow variability measurements for epidemiologic studies. Am Rev Respir Dis 1992; 145:588-93.

35 Brand PL, Postma DS, Kerstiens HA, et al. Relationship of airway hyperresponsiveness to respiratory symptoms and diurnal peak flow variation in patients with obstructive lung disease. The Dutch CNSLD Study Group. Am Rev Respir Dis 1991;143:916-21.

36 van Noord JA, Bantje TA, Eland ME, et al. A randomised controlled comparison of tiotropium and ipratropium in the treatment of chronic obstructive pulmonary disease. The Dutch Tiotropium Study Group. Thorax 2000;55:289-94. 